\title{
Cocaine to Procaine: An Unexpected History of Local Anaesthesia
}

\author{
Sophie Johnson* \\ Department of Anesthesiology, The Aagbi Foundation, London
}

Received: 眥 July 18, 2018; Published: 眥July 24, 2018

*Corresponding author: Sophie Johnson, Association of Anaesthetists of Great Britain, Ireland, The Aagbi Foundation, 21 Portland Place, London, W1b 1py.

\section{Short Communication}

Like many types of medicine, local anaesthesia has very interesting origins. It seems slightly mad today that substances were more likely to associate with youth rave culture than our local GP, were once, not only legal, but readily available as analgesics for a wide range of ailments. At the Anaesthesia Heritage Centre, we have cocaine and morphine 'tabloids' for example, which could have been used for various pains; cocaine is even known to have been prescribed for morning sickness. Cocaine was the first substance noted for its local anaesthetic qualities. Coca leaves were first brought to Europe from South America around the mid-1800s and cocaine was isolated soon after by German chemist Albert Neimann. It was psychoanalyst, Sigmund Freud, who suggested cocaine to his friend and ophthalmologist, Carl Koller. Freud had been using cocaine on his patients and would inevitably become addicted to the substance himself. Koller went on to be the first person to publish cocaine's anaesthetic qualities in 1884 when he used it as eye drops during eye operations.

\section{IMAGE: Cocaine Tabloid Tube c. 1920-40}

These 'tabloids' were made by pharmaceutical company Burroughs Welcome \& Co. and designed to be liquefied on a spoon. Local anaesthetic drugs would've had very restrictive use however, without the development of syringes and needles which made regional blocks possible. The glass syringe and hollow hypodermic needle was first developed independently by Alexander Wood of Edinburgh and Charles Gabriel Pravaz of France in 1853. It would be a century before these traditional glass instruments were replaced with the disposable plastic ones we are familiar with today (Figure 1).

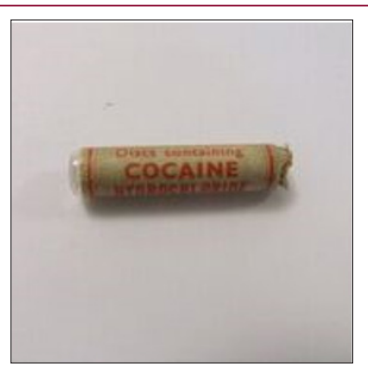

Figure 1: Cocaine tabloid tube c. 1920-40.

\section{IMAGE: Hypodermic Needles. 40's - 60's}

These needles and syringe were used between the 1940s and 60s. Until the 1960s the majority of needles and syringes used outside of warfare, were re-useable and supplied un-sterilised. It may come as no surprise that there were downsides to cocaine. Not only did patients become addicted to the substance but so did many of the doctors who researched the drug by being guinea-pigs themselves. The substance was extremely toxic and substitutes for cocaine shortly followed. Giesel's tropococaine appeared in 1891, Fourneau's stovaine in 1904, and Einhorn's procaine (Novocaine) in 1904 which was later popularised by Hernich Braun in 1905 (Figure 2).

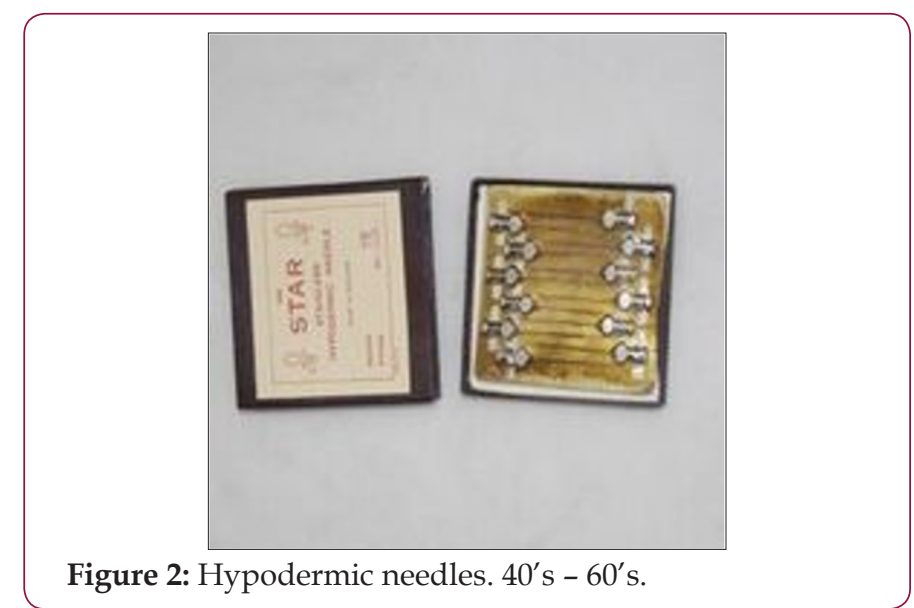

\section{The development of Spinal Analgesia}

Like many great scientific discoveries, spinal analgesia was discovered accidentally by J. Leonard Corning in 1885 when injecting cocaine into a dog and accidentally causing paralysis of the hindquarters. The first planned human spinal analgesia for surgery was later administered by August Bier in 1898 and popularised by Gaston Labat in 1921. It took a while for spinal analgesia to become popular owing to the toxicity of cocaine. A more recent development in the field has been epidural analgesia, where nerve roots are blocked from the spinal cord with pain-killing medication. The first epidural block was performed in 1921 by Spanish military surgeon, Fidel Pagés. 


\section{IMAGE: Labat Spinal Set}

Labat designed a spinal needle that was made of unbreakable nickel. It had a short, sharp bevel which acted as a wedge, pushing tissues aside rather than cutting them, and therefore minimising damage to the dura (Figure 3).

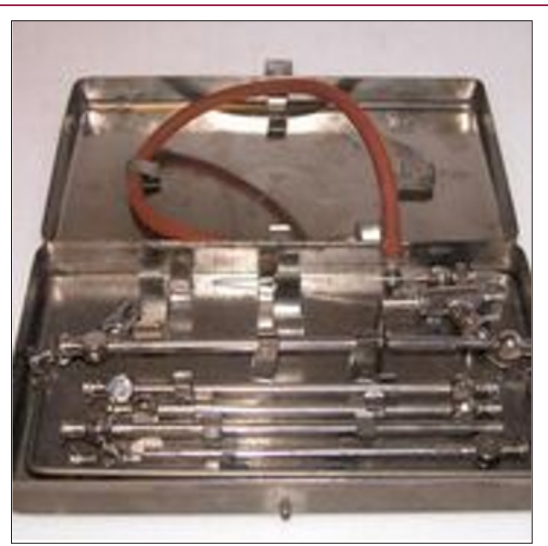

Figure 3: Labat spinal set.

\section{IMAGE: Nupercaine Ampoules}

Nupercaine is an amide-type local anaesthetic, similar to lidocain. It is very potent and long-lasting and used exclusively for spinal anaesthesia (Figure 4).

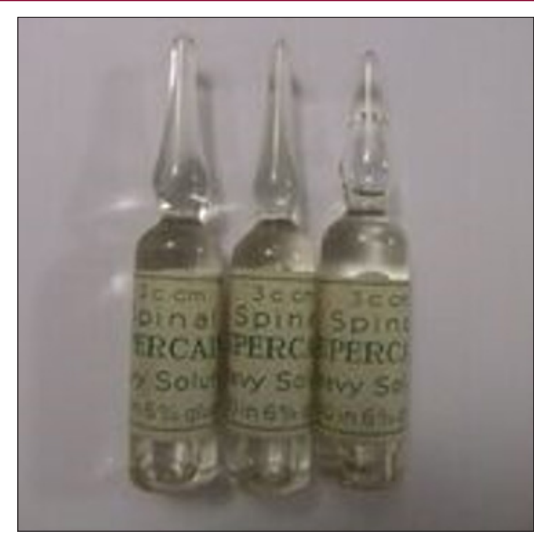

Figure 4: Nupercaine ampoules.

\section{Regional Anaesthesia in Obstetrics}

Before epidural anaesthesia, general anaesthesia had been used during childbirth for many years. Famously, John Snow administered chloroform to Queen Victoria during the birth of her last two children. After the royal seal of approval this method became quite popular. Fidel Pagés' technique for lumbar epidural anaesthesia was popularised in the 1930s by Achille Dogliotti, best known for his 'loss-of-resistance' technique. George Pitkin was the first to use "controllable" spinal anaesthesia for delivery in 1928, and in 1931 Romanian surgeon, Eugène Aburel Bogdan, was the first to describe blocking the lumbar plexus during early labour, followed by a caudal epidural injection during the expulsion phase.

\section{IMAGE: Pitkin tiltometer, 1955}

George Pitkin discovered complications with low blood pressure during controllable spinal anaesthesia could be avoided by putting the patient in the Trendelenburg position (feet higher than head). He created the tiltometer to accurately gauge the ideal degree. In 1941, American anaesthesiologist Robert Andrew Hingson collaborated with obstetrician Waldo B. Edwards, to study the use of continuous caudal anaesthesia during childbirth. Rather than removing the caudal needle after the injection as was customary, Hingson and Edwards studied the caudal region to determine where a needle could be placed to deliver continuous anaesthetic agents safely to the spinal nerves. This method was first performed on a woman in 1942 for an emergency Caesarean section. In 1947 Cuban anaesthesiologist, Pío Curbelo, first described the use of a lumbar epidural catheter. This allowed the needle to be removed and the anaesthetic to be administered through a catheter. Despite this being the most efficient method, it took nearly two decades for lumbar epidural anaesthesia to replace continuous caudal anaesthesia due to the lack of sterile single use plastic tubing. The availability of sterile single use plastic tubing started the era of epidural analgesia in labour (Figure 5).

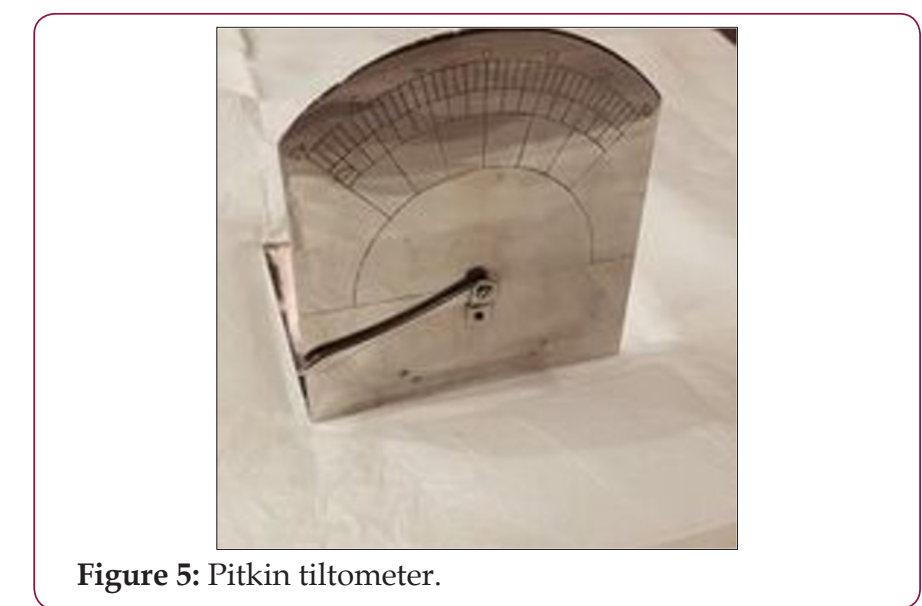

\section{Dental Anaesthesia}

The first ever documented general anaesthetic administered was for a dental extraction in 1846. However, the development of local anaesthetic at the turn of the century would revolutionise dental practice. In 1884 R.J. Hall and William Halsted experimented with local anaesthesia during dental surgery. Hall wrote to the New York Medical Journal about successfully having his tooth filled after cocaine was injected to numb the area, without any pain or discomfort. In 1905, procaine (branded Novocaine) was created by Einhorn and Uhfelder in Germany, as a safer, non-addictive alternative to cocaine and became the local anaesthetic of choice in dentistry (and across the board). Procaine was widely used by dentist's right up until the invention of lidocaine in the 1940s. Lidocaine is less likely to cause allergic reactions than procaine and it's still one of the most popular local anaesthetics used in dentistry.

\section{IMAGE: Novocaine (procaine)}

Novocaine is the brand name for procaine. It was the first and subsequently best-known substitute for cocaine. It is not addictive, toxic or irritating, but as part of the amino ester group of drugs, allergic reactions are common. The development of local anaesthetic practice revolutionised surgery. Without it we wouldn't have many 
of the routine procedures that are so common today. Every time you go to the dentist or have localised surgery; remember where you would be without the pioneers of the past perfecting the technique of local anaesthetic (Figures 6-8).

Figure 6: Novocaine (procaine).
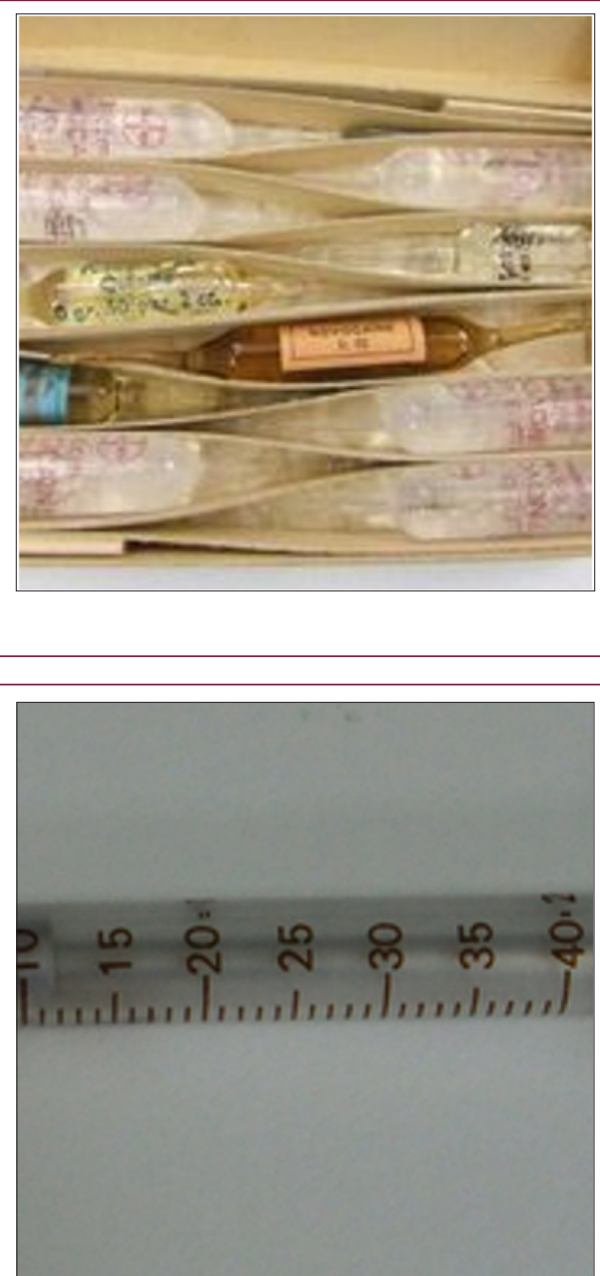

Figure 7: Glass Syringe.

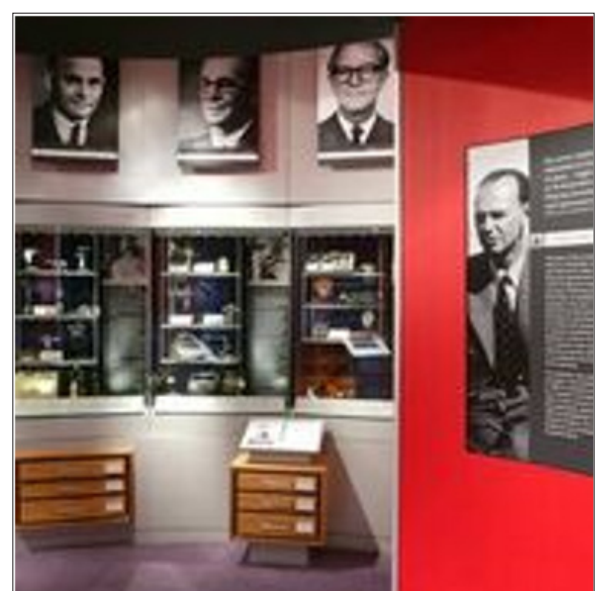

Figure 8: Anesthesia-Heritage-Centre. 
ISSN: 2574-1241

DOI: 10.26717/BJSTR.2018.07.001467

Alexander Brenner. Biomed J Sci \& Tech Res

(C) This work is licensed under Creative

Submission Link: https://biomedres.us/submit-manuscript.php

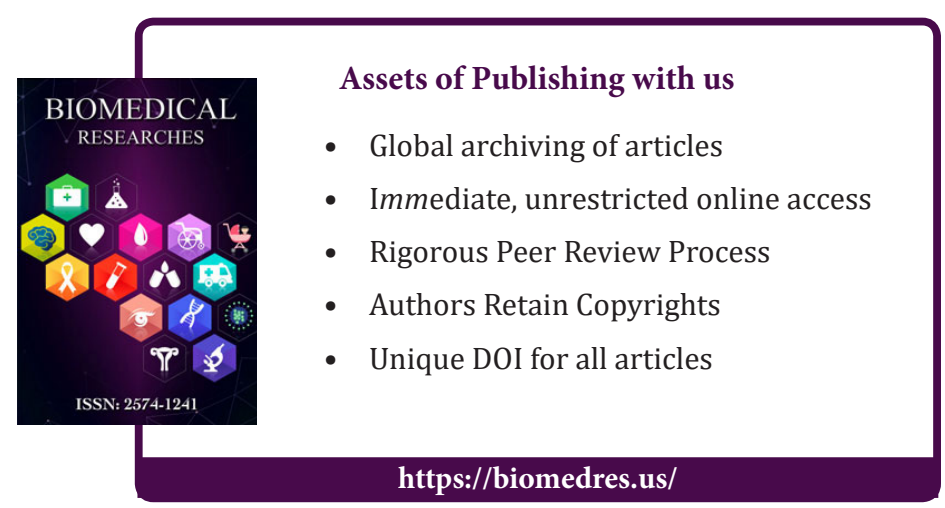

